\title{
Global Competency Through Collaborative Online International Learning (COIL)
}

\author{
Jessica M. Harris ${ }^{1}$, Minjung Seo ${ }^{1}$, Joshua S. McKeown ${ }^{2}$
}

${ }^{1}$ Department of Health Promotion and Wellness, The State University of New York at Oswego (SUNY Oswego), USA, ${ }^{2}$ Office of International Education and Programs, The State University of New York at Oswego (SUNY Oswego), USA.

\begin{abstract}
There is a need for college students to develop global perspectives and gain cultural awareness to become responsible global citizens. Innovative ways to create such experiences are known as Collaborative Online International Learning (COIL experiences). COIL is a voluntary partnership between professors in different countries collaborating on jointly constructed learning experiences to enhance international and intercultural understanding. The purpose of this article is to highlight a successful COIL partnership between students from SUNY Oswego in New York and The Hague University of Applied Sciences in the Netherlands during the COVID-19 pandemic. 35 students participated in the experience that served as a platform to educate students through a health educator's unique cultural lens. Benefits from the experiences regarding global outcomes showed that both US students $(n=70.6 \%)$ and Holland students ( $n=61.1 \%$ ) felt they gained the appropriate skills and knowledge to use in their future careers. $70.6 \%$ of US and $61.2 \%$ of Holland students reported that the COIL experience introduced them to a new outlook and new ways of thinking about how they relate to the world. The current COVID-19 pandemic has created an opportunity to rethink education pathways and integrate global learning in our classrooms.
\end{abstract}

Keywords: Global learning; COIL; partnerships, collaboration. 


\section{Introduction}

\subsection{Importance of Global Perspectives in Higher Education}

Today college students need to develop global perspectives, where they think and act in terms of living in a world where they collaborate, work, and live with individuals from various cultures, backgrounds, perspectives, values, and beliefs (Braskamp, Braskamp, \& Merrill, 2009). Higher education leaders acknowledge that their graduates will face challenges with growing urgency, resulting in the vital development of intercultural competence and global learning for effective participation and leadership in an increasingly complex and diverse global environment (Earnest, 2003). Many institutions increasingly internationalize their curricular and co-curricular efforts on campuses (Soria \& Troisi, 2014) to deepen students' connections as responsible citizens in a global context. For example, the State University of New York (SUNY) system created such experiences as Collaborative Online International Learning (COIL). It was made a formal educational priority by establishing the SUNY COIL program center in 2006 (SUNY COIL Center, 2017).

\subsection{Collaborative Online International learning}

At its core, COIL is the concept of voluntary partnership between professors in different countries collaborating on jointly-constructed learning experiences to make their individual courses stronger through enhanced international and intercultural understanding. Rather than being only based on institutional contracts or agreements, enacted by permanent bureaucracies and vetted by legal counsels, the essence of COIL is a reliance on willing and likeminded faculty colleagues worldwide who are eager to bring classrooms, projects, and performances together through technology. This nodal network of global academics has become indispensable during the COVID-19 pandemic, during which nearly all traditional academic and student mobility has halted worldwide; indeed, COIL may have found its moment to realize its long-imagined potential to transform globalization in education. A successful COIL partnership can be formal or informal; it need not require a written agreement or memorandum of understanding (MOU). The student-to-student interaction can occur through any reliable communication platform, and travel by faculty or students is not required. Perhaps most importantly, there need not be any additional cost to operate a COIL course. These aspects make COIL a compelling program model, especially for students unable to travel internationally for whatever reason on traditional study abroad programs. The following presentation of a successful design and implementation model will be of interest to Senior International Officers (SIOs) of universities and others responsible for curricular integration in fulfilling their existing institutional goals in this new format (Leask \& Green, 2021; Pinder, 2019). 


\subsection{The Current Research}

This article highlights the successful COIL partnership between SUNY Oswego and The Hague University of Applied Sciences, a carefully constructed and rigorously assessed partnership example that can serve as a potential model for enhanced global education. Building on established principles for international program planning (McKeown, 2014) and partnership-building (Gorlewski, 2014) modified and implemented for the COIL environment, this partnership embodies what makes a successful COIL relationship unique. It is especially important during the time of the COVID-19 global pandemic when so much of virtual and remote instruction worldwide was transitioned to rapidly and done so out of necessity (Altbach $\&$ de Wit, 2020); this course was purposefully planned and designed to facilitate online learning and community-building across borders based on a willing relationship, not travel. Even the disruption of COVID-19 during the course was not a deterrent to this approach, indeed learning flourished in this COIL context where it often suffered in others.

\subsection{Globalization in Education and Education Reform}

As a model to enhance globalization in education, COIL's potential has received renewed emphasis during COVID-19. International education thought leaders and practitioners have noted that COIL and other virtual global learning forms are likely here to stay (Kahn, 2020). Indeed, the virtual educational world that emerged through technology more broadly during the pandemic was an inescapable and pervasive new facet of life required to support the continuation of academic activities, which previously relied primarily on face-to-face interactions (Chan, 2020), including international mobility through traditional study abroad and exchange programs. Technology-mediated educational delivery can also be seen as an attempt to build communities and foster a sense of awareness and belonging in people that typically would take place through intense in-person experiences that became a real alternative during the pandemic (Reed \& Dunn, 2022). Despite the urgent concerns about inequities in access to and literacy in technology worldwide (Chan, Bista, \& Allen, 2022), COIL can also be seen as a way to help address access issues and inequities in international education, travel restrictions, and enhance global learning for all in the curriculum.

However, at this moment, it is recognized that little data exist showing the efficacy of this form of international education and the extent to which COIL experiences differ from traditional in situ experiences (Whalen, 2020). Also, it has been noted that faculty particularly need guidance on how to construct and deliver such experiences (Duke, 2020). This article seeks to contribute to this growing and vital conversation on how best to identify effective COIL practices post-pandemic in order to bring accessible and equitable global learning for all. 


\section{International Teaching and Learning From New York to the Netherlands}

\subsection{Purpose}

The underlying motivation for creating an international learning experience was to help students from two countries gain cultural competence and offer a global perspective in their field of health promotion and wellness. Specifically, health educators have a duty and responsibility within their code of ethics to deliver health education that considers all individuals' cultural backgrounds and practices, thus creating an opportunity for a collaborative online international learning experience to foster and grow.

\subsection{Approach}

Through networking at a COIL conference held in New York City in 2018, two professors from the Netherlands and the US met to create and design a COIL experience in health promotion. The experience joined SUNY Oswego students from the Department of Health Promotion and Wellness and students from The Hague University of Applied Science from the Nutrition and Dietetics program. The professors designed this course around three primary elements of pedagogy, intercultural learning, and technology (The SUNY Center for Collaborative Online International Learning, 2019). Emphasis was placed on the collaborative process between the students to create shared experiences and understanding around health promotion standards. The professors developed a collaborative project where students would utilize technology to communicate and exchange cultural and experiential lenses while they process and move through learning material together.

The course established student collaboration to understand how health educators in different countries contribute to global health processes and communicate their ideas and values clearly and effectively with diverse audiences. A total of $(\mathrm{N}=35)$ undergraduate students from both institutions participated during the Spring of 2020. Of these participants, 17 were US students, and 18 were Holland students. The learning objectives of the COIL experience were to: (1) Facilitate an understanding and appreciation of cultural differences between the United States, and Holland, (2) Learn about lifestyle and health promotion from a diverse perspective, (3) Build intercultural communication skills by practicing interviewing techniques, (4) Acquire digital communication skills, (5) Connect with students from another country and form new relationships, (6) Develop cultural sensitivity to understand individuals from another culture better, and (7) Build skills to attain cultural competence. Students were paired with a student from the opposite country by random to ensure cross-cultural collaborations. Students then collaborated for six weeks on various health promotion assignments through virtual modalities. 


\subsection{Curriculum}

The focal point of this COIL experience consisted of a cross-border collaborative project that was broken into various tasks and small assignments. Each of these tasks and assignments created a cumulative PowerPoint showcasing the students' global work concerning their discipline of health promotion. This project was designed to compare and contrast physical activity, behavior, and nutrition issues through an international lens. The first step in the process was introducing the two classes from across borders virtually in the classroom via Skype. Students then initiated contact through various technological modes setting up their first oneon-one virtual meeting. Before the first meeting, each student was required to bring pictures and videos of the target population they were studying to share. Students discussed the photos and videos analyzing similarities and differences regarding lifestyle issues in each other's country. The next virtual meeting, students discussed predisposing, reinforcing, and enabling factors of behavior, focusing specifically on nutrition and physical activity in the two cultures. Students analyzed differences regarding diet patterns and physical activity between the two countries. Another virtual exchanged, helped students critically analyze governmental health guidelines within both countries and environmental factors that contributed to the health behaviors they had been discussing. In the final meeting students shared their goals and objectives for the evidence-based health promotion program they have been planning that would aid in behavior change for their target populations. Outcomes showed that students had a better understanding of global governance systems and proper knowledge to solve societal health problems in ethical ways. At the end of the 6-week experience, students created a 10- slide PowerPoint Presentation that highlighted the commonalities and differences among people and cultures and how these factors influenced their cultural perspectives on health.

\subsection{Technologies Used}

This technology-rich learning environment that housed the COIL experience for students from both countries enhanced student performance and fostered deeper understanding because of their ability to communicate effectively and efficiently with their international partners. A proprietary learning management system (LMS), such as Blackboard, was a costeffective solution to developing our global partnership. The learning management system (LMS) Blackboard was utilized and hosted by SUNY Oswego, allowing for secure access for The Hague University of Applied Science Students to use, communicate, and submit assignments. This system was already existing and available for free. Campus Instructional Designers were able to assist in setting up the course shell, making it accessible to both institutions, and solving any technical issues encountered. There are various open access thirdparty technologies available to use for a COIL course. Still, there has not been significant evidence or research explaining the possible security risks to student data or other private information when using these technological tools (Zhang \& Pearlman, 2018). Thus, making 
blackboard the most appropriate platform that had no restrictions for our partner institution and was equitable and seamless in the integration.

Another technological tool introduced by the Holland instructor was Padlet. This free online tool is consistent with a 'notice board.' Students shared images of their favorite foods and interests to build community and facilitate engagement. A variety of online collaboration tools can be used, but it is important to keep in mind how equitable the tool may be for students from both institutions. Using free applications or tools can help keep things simple and feasible for all students. This is why many of our students communicated virtually with their partners through applications such as Facetime, Skype, Zoom, WhatsApp, Google Voice, Rebtel, and Vonage, which offer either free or low-cost video chat and communication methods. Other technologies aided in creating the collaborative project, such as Google Drive, PowerPoint, and Microsoft Software Systems. These systems were also available to both institutions, and students were able to navigate through their tasks and assignments with their international partners.

Overall, $57.1 \%$ of the students agreed and stated that they felt prepared to meet the technology demands of the COIL component in the course, while $17.1 \%$ strongly agreed with that statement. Students also agreed and thought that the technology chosen for this COIL component was appropriate for the needs of the experience, and $28.3 \%$ strongly agreed with this statement.

\section{Lessons Learned}

This COIL experience served as a platform to educate students through a health educator's unique cultural lens. Students built on knowledge and developed diverse personal relationships by negotiating meaning when working in virtual teams (Fowler, Pearlman, LeSavoy, $\&$ Hemphill, 2014). There were many benefits from this experience regarding student global learning outcomes. For example, 58.8\% of US students reported that they made such significant connections with their international partners to maintain that relationship and friendship beyond the course. Holland students reciprocated this feeling, with $44.5 \%$ stating the same. Students reported that the COIL experience provided them with the skills and knowledge they will use in the future and within their careers (US students $n=70.6 \%$; Holland students $\mathrm{n}=61.1 \%$ ). $76.5 \%$ of US students and $61.2 \%$ of Holland students reported that the COIL experience introduced them to a new outlook and new ways of thinking about how they related to the world. COIL experiences increase intercultural awareness and online intercultural communicative competence. These experiences also better prepare students for careers and civic engagement in the global context (Zhang \& Pearlman, 2018). Students participated in this experience during the very beginning of the COVID-19 pandemic. They were able to create close bonds and conversations with their partners and discuss the state of the pandemic in 
each country. The circumstances surrounding COVID-19 presented a unique opportunity for virtual exchanges that resulted in international shared experiences and socialization without worrying about safety or financial barriers due to travel.

\subsection{Limitations}

A limitation of this COIL course that also turned out to be an opportunity in many ways was the COVID-19 pandemic. There were some challenges associated with Wi-Fi interconnectivity once students transitioned to remote learning at home. However, the pandemic offered students a valuable opportunity to discuss in real-time the impacts COVID-19 was having on different parts of the world. English was the preferred and common language; however, students had mentioned varying proficiency levels when working with their partners. Students also reflected upon the time difference between New York and The Netherlands, where there was a six-hour time difference.

\subsection{Moving Forward: The COVID Re-Invention}

Amidst a current public health crisis, Colleges and Universities are navigating remote learning and creatively bringing back some sense of normalcy for their students. Many have been forced to work from home shifting our conceptions, resulting in the possibility of new avenues for our future generations where virtual global collaborations are day-to-day job commitments. Educators are creating health promotion programs through a computer lens, and students are acquiring new transferable skills that prepare them for co-workers they never meet in person. These situations create opportunities to rethink educational pathways by using global learning initiatives as an integrative theme (Hovland \& Schneider, 2011).

\section{References}

Altbach, P. G., \& de Wit, H. (2020). Responding to COVID-19 with IT: A transformative moment? International Higher Education, 103, 3-4.

Braskamp, L. A., Braskamp, D. C., \& Merrill, K. C. (2009). Assessing progress in global learning and development of students with education abroad experiences. Frontiers: The Interdisciplinary Journal of Study Abroad, 13, 101-118.

Chan, R. Y. (2020). Studying coronavirus (COVID-19) and global higher education: Evidence for future research and practice (June 1, 2020). Available at SSRN: https://ssrn.com/abstract=3622751 or http://dx.doi.org/10.2139/ssrn.3622751

Chan, R.Y., Bista, K., \& Allen, R.M. (2022). Epilogue: The future of online teaching and learning in higher education after COVID-19: Lessons learned and best practices. In R.Y.

Chan, K. Bista, \& R. M. Allen (Eds.), Online teaching and learning in higher education during COVID-19: International perspectives and experiences. Routledge.

Duke, S. E. (2020). Intercultural learning: A 2020 perspective. Retrieved from https://www.nafsa.org/ie-magazine/2020/12/9/intercultural-learning-2020-perspective 
Earnest, G. W. (2003). Study abroad: A powerful new approach for developing leadership capacities. Journal of Leadership Education, 2, 2-14.

Fowler, J. E., Pearlman, A. M. G., LeSavoy, B., \& Hemphill, D. (2014). Opening SUNY to the world: Implementing multi-cultural curricular internationalization through the COIL network case studies from SUNY Oswego and College at Brockport. Cornell University, Ithaca, NY, May 27-30, 2014. The 23rdSUNY Conference on Instruction and Technology.

Hovland, K., \& Schneider, C. G. (2011). Deepening the connections: Liberal education and global learning in college. About Campus, 16(5), 2-8.

Kahn, H. E. (2020). Global teaching and learning: A 2020 perspective. Retrieved from https://www.nafsa.org/ie-magazine/2020/12/10/global-teaching-and-learning-2020- perspective

Leask, B., \& Green, W. (2021). Curriculum integration: Maximizing the impact of education abroad for all students. In A.C. Ogden, B. Streitwieser, \& C. Van Mol (Eds.), Education abroad: Bridging scholarship and practice (pp. 169-183). Routledge. Bloom, B. S. (1956). Taxonomy of Educational Objectives. New York: David McKay.

McKeown, J. (2014). Strategic planning for education abroad programs. In M. Hernandez,M. Wiedenhoeft, \& D. Wick (Eds.), Nafsa's guide to education abroad for advisers and administrators (4th ed., pp. 213-226). Nafsa.

Pinder, A.L. (2019). Curriculum internationalization. In D. L. DiMaria (Ed.), Senior international officers: Essential roles and responsibilities (pp. 153-164). Nafsa.

Reed, J., \& Dunn, C. (2022). Life in 280 characters: Social media, belonging, and community during the Covid-19 pandemic. In R. Y. Chan, K. Bista, \& R. M. Allen (Eds.), Online teaching and learning in higher education during COVID-19: International perspectives and experiences. Routledge.

Soria, K. M., \& Troisi, J. (2014). Internationalization at home alternatives to study abroad: Implications for students' development of global, international, and inter-cultural competencies. Journal of Studies in International Education, 18, 261-280. doi:10.1177/1028315313496572

SUNY COIL Center. (2017). A brief history of the SUNY COIL center. Retrieved from http://devcoil.suny.edu/page/brief-history-suny-coil-center

The SUNY Center for Collaborative Online International Learning. (2019). Guide for collaborative online international learning course development. http://www.ufic.ufl.edu/UAP/Forms/COIL_guide.pdf

Whalen, B. (2020). Education abroad in a post covid-19 world. Retrieved from https://www.insidehighered.com/views/2020/04/14/how-covid-19-will-change education-abroad-american-students-opinion

Zhang, J., \& Pearlman, A. M. G. (2018). Expanding access to international education through technology enhanced collaborative online international learning (COIL) courses. International Journal of Technology in Teaching and Learning, 14(1),1-11 